\title{
The Temporality of Maximal Grip: On Pragmatists' Readings of Merleau-Ponty
}

\author{
DANIIL KOLOSKOV \\ Université catholique de Louvain, Charles University in Prague \\ $\triangle$ dankol.94@mail.ru
}

\begin{abstract}
In this article, I will pursue three aims. First, I would like to demonstrate the non-transcendental character of Merleau-Ponty's phenomenology, namely, his claim that a strict division between a priori and a posteriori is an abstraction that derives from a more primordial unity that is given in our lived experience. I will criticize authors such as H. Dreyfus and T. Carman who treat the body and bodily character of our existence as a classical Kantian a priori that functions as a condition of experience without itself being a part of the experience. The claim I would like to defend in this regard is that reflections on the conditions of our experience must themselves be a part of our experience. The second task is to show how Merleau-Ponty's analysis of temporality helps him to avoid this strict division between a priori and a posteriori. Based on this, I will elucidate some of the most obscure passages of Phenomenology of Perception. Finally, I will claim that the notion of optimal grip can neither be explained by the reference to our body, as Carman claims, or to brains, organisms and their copings with the environment, as Dreyfus argues. Instead, I will claim that the maximal grip is rather a consolidation or intensification of the temporal ecstasy.
\end{abstract}

Keywords transcendental philosophy, Merleau-Ponty, Dreyfus, optimal grip, Carman, body. 


\section{Introduction}

A thing, says Merleau-Ponty, has its specific traits: colour, size, form, etc. The peculiar fact about this is that those specific traits seem to be changeable and even elusive. A white table, for example, appears very differently under different lightening conditions. Similarly, a cube may appear as a square. However, we still identify them unequivocally as white and as a cube without second thoughts. How is this possible? How are we capable of ascribing to things some determinate forms that belong to them essentially? One way of finding a way around this problem is to treat such changeability as a deficiency. We could suppose that there is something like the objective size or the objective form that belong to objects in themselves and, thus, subscribe to what MerleauPonty calls empiricism, or we could stand on the side of intellectualism and claim that these true elements are simply obtained in the concept that we apply to them. In both cases, we would postulate something like a ground (either empirical or intellectual) that unifies all the changeable manifestations of things. So, when a table appears to me as grey, I know that in reality it is white and only appears differently because of the light. When I see a diamond, I recollect that this is a square only seen from a particular perspective. I deduce and distil the perspectival influences on my perception to get to the object in itself. The perspectival and changeable character would only be a necessary limitation placed upon the perception, which must be overcome. According to such a position, we rather think the perception through than actually perceive it. Perception, then, would indeed be a science in nuce. ${ }^{1}$

There is a number of things wrong with this conception. For one thing, we never actually attain such a scientific attitude to reality except in marginal circumstances. The Schneider case gives a good example of how counter-intuitive such constant enquiring of reality is. When asked to perform an abstract movement (or when faced with unusual circumstances), Schneider's flow of experience was frequently interrupted: under unusual, unhabitual circumstances he was never aware of what he was facing until he deduced the content with the help of logical reasoning (it's thick and long, it must be a pencil). ${ }^{2}$ The abstract understanding was only possible for him based on a systematic deduction. A healthy individual, on the contrary, does not have to reason out what he sees and feels for the most part. What we see is already a cube or a white table: things are already there when we first discover them. We do not

${ }^{1}$ M. Merleau-Ponty, Phenomenology of Perception, Engl. transl. by D.A. Landes, Routledge, 2013, p. 65.

${ }^{2}$ Ibid., p. 151. 
constitute them but see them already constituted. This demonstrates that there must be a more primordial cohesion between the human existence and the world than both empiricist and intellectualist strategies have supposed.

How, then, do things come up with determinate forms and qualities? How can we grasp the real sizes and qualities of objects if we cannot complement these objects by postulating either things in themselves or ideal concepts behind their appearances? The answer, as I will try to demonstrate in this paper, can be explicated based on Merleau-Ponty's notion of maximal grip. According to him, there is a certain point of optimality where a perceived object discloses itself in the most revealing way. This optimality is not a ground behind the appearances but rather a rule or a norm, as S. Kelly has argued, ${ }^{1}$ around which all the particular perceptions of this object are organized. All these perceptions are guided by the tendency to attain the optimal position that will give us a better look on the object. The deviations from this point are perceived as abnormalities - as too close, too far, etc. The optimal point presupposes suboptimal ones. Every perception, in such a way, contains a certain rule or "conditions of improvement," 2 as Dreyfus puts it, a rule that indicates a direction towards a more revealing perspective. Perception of an object gravitates towards this point of optimality. The gravitation is not a matter of logic. It is rather bodily in nature: I am inclined to attain the optimal position often without any explicit recognition. But again, what defines which appearance of an object can be count as optimal? How can we differ more and less revealing appearances? This will be the central question of the following sections.

\section{Maximal grip and grounding in body}

Pragmatists readers such as H. Dreyfus, M. Wrathall, T. Carman, C. Taylor and others seem to have one possible answer to this question. (In this article, I will mostly address the interpretations proposed by T. Carman and H. Dreyfus for the sake of brevity. I believe, however, that such an approach has a wider representation among scholars.) Their claim, if I may put it in quite an oversimplified fashion, is that it is my body that one-sidedly guides me through the world. Bodily capacities and skills create a certain space of meaningfulness, within which meanings are ascribed to entities, thus, letting our intentionality

${ }^{1}$ S. Kelly, "Seeing things in Merleau-Ponty," in: Roberto J. Carman et al. (ed.), The Cambridge Companion to Merleau-Ponty, Cambridge University Press, 2005, p. 97.

${ }^{2}$ H. Dreyfus, "Overcoming the Myth of the Mental," in: H. Dreyfus \& M.A. Wrathall, Skillful Coping, Oxford University Press, 2014, p. 104. 
unfold. Even though Phenomenology of Perception might occasionally seem like implying this sort of position (especially if the first two chapters are considered), I will try to demonstrate that such an understanding is at least partial and shouldn't be taken as Merleau-Ponty's final word. So, let's first take Carman's reading. In his article "Sensation, Judgment, and Phenomenal Field," he rightly notes,

body and world are conceptually, not just causally, two sides of the same coin. The world and I are intelligible each only in light of the other. My body is perceptible to me only because I am already perceptually oriented in an external environment, just as the environment is available to me only through the perceptual medium of my body. ${ }^{1}$

Already in the next passage, however, he adds,

our bodily orientation and skills constitute for us a normatively rich but noncognitive relation to the perceptual milieu. ${ }^{2}$

As we can see, Carman believes that body and the world are indivisible, and that body is indeed unconceivable without the world. This does not mean, however, that both sides of the equation are placed on an equal footing here. Bodily orientations and skills constitute or "underlie" our perceptual orientation in the world; body is taken as something that has explanatory priority. Because we have specifically structured bodies, we end up having the correspondingly structured world. Body "establishes a normative domain without which perception could not be intentional." ${ }^{3}$ Carman, therefore, explains our relations with things and our tendency to get the optimal grip on them by the reference to the structure and disposition of our bodily capacities and skills.

Dreyfus holds a similar but slightly more advanced position. Just like Carman, Dreyfus believes that the way experience is synthesised finds its explanation in our bodies. He first speaks of a particular structure of our "brain architecture" that responds to a certain type of "inputs" from the environment. So, we react to heat and colours because it is somehow wired into our brains and we do not react to electromagnetic waves (for the most part) because our

${ }^{1}$ T. Carman, "Sensation, judgement and phenomenal field," in: The Cambridge Companion to Merleau-Ponty, p. 68.

${ }^{2}$ Ibid., my emphasis.

${ }^{3}$ Ibid., p. 70, my emphasis.

${ }^{4}$ H. Dreyfus, "Merleau-Ponty and recent cognitive science," in: H. Dreyfus \& M.A. Wrathall, Skillful Coping, p. 237. 
brain lacks appropriate structures to process inputs of this sort. Secondly, inputs do not directly define outputs. Because organisms are capable of systematizing and organizing inputs, the way they are transformed into outputs is mediated. This mediation, claims Dreyfus, is realized based on the maximization of reward. ${ }^{1}$ Because organisms are living beings that need to sustain their existence, their experiences always appear as rewarding or unrewarding, i.e., as helping or obstructing their survival. Consequently, organisms are capable of processing the inputs in order to maximize rewards and minimize dissatisfaction, thus, arriving to more complex and beneficial forms of behaviour. They always have, says Dreyfus, this felt sense of equilibrium that tells them if they deviate from the optimal course of action. The first fundamental layer of intentionality gets cultivated on the second, normative level that prescribes optimal behaviour. Reward as such is possible because we have a certain brain structure, but the way the reward is reached is defined by the learning process that every individual organism comes through. The primordial first-level intentionality, says Dreyfus, is what differs people from neural networks: networks are capable of learning, but they lack this bodily level that motivates us to search for reward in the first place.

Such an interpretation has been criticized for a number of reasons. J. Čapek has argued that pragmatists' emphasis on organisms and their "coping" with the environment results in losing Merleau-Ponty's original emphasis on the transcendence of a thing. ${ }^{2}$ J.C. Berendzen ${ }^{3}$ and K. Romdenh-Romluc ${ }^{4}$ have shown that Dreyfus mistakenly ascribes to Merleau-Ponty a claim according to which practical coping grounds higher-order theoretical intentionality. Merleau-Ponty, in fact, never subscribed to this "layer cake" model of intentionality and shouldn't be considered as a foundationalist of any sort, as Berendzen and Romdenh-Romluc have demonstrated. Also, Romdenh-Romluc and O. Švec have demonstrated that embodied coping should account for a certain responsiveness to reasons. ${ }^{5}$ These articles undoubtedly demonstrate serious shortcomings in pragmatists' reading of Merleau-Ponty. However, I want to take a slightly different course of criticism, which presupposes but does not

${ }^{1}$ Ibid., p. 243.

2 J. Čapek, "Perceptual faith beyond practical involvement," in: O. Švec \& J. Čapek (eds.), Pragmatic Perspectives in Phenomenology, Routledge, 2017, p. 149.

${ }^{3}$ J. C. Berendzen, "Coping without foundations: On Dreyfus's use of Merleau-Ponty," International Journal of Philosophical Studies, Vol. 18, 5 (Dec. 2010), p. 629-649.

${ }^{4} \mathrm{~K}$. Romdenh-Romluc, "Thought in action," in: D. Zahavi (ed.), The Oxford Handbook of Contemporary Phenomenology, Oxford University Press, 2013.

${ }^{5}$ O. Švec, "Situated acting and embodied coping," Pragmatism Today, Vol. 11, 2 (September 2020). 
limit itself to the mentioned papers. Before I start, first I'd like to say a few more words on another recent work by S. Loidolt that raises even more substantial objection against Dreyfus. Namely, she claims that Dreyfus's emphasis on brains and bodies, eventually, runs counter to the most fundamental phenomenological maxima - adherence to the first person of view. Dreyfus's emphasis on mindless coping, non-conscious being-in-the-world, "brain" that somehow "detects" stimulus only demonstrates that his approach fits more neurobiological research than the actual phenomenological investigation. ${ }^{2}$ Although I think that Loidolt is on the right track here and that she attempts to explicate the core of the problem, in my opinion, she is probably too harsh on Dreyfus. After all, Dreyfus is a phenomenologist, and it would be completely odd if he ended up with such a thoroughly non-phenomenological approach, thus, ignoring all the criticisms that Heidegger, Husserl and Merleau-Ponty have risen against it. The problem, I think, is more complicated than this as it hides at the level of their presuppositions.

Let's take a look, for example, at the following passage in T. Carman's mentioned article:

In the Schematism chapter of the first Critique, Kant conceived of schemas as organizing principles for the construction of images, principles he thought played an essential role in constituting the objectivity of experience. For Kant, however, a schema could play that structuring role only by being an explicit rule, a kind of cognitive content. So, although Merleau-Ponty's theory of intentionality is nonrepresentational and noncognitive, his concept of the body schema is analogous to Kant's insight that intentional content does not just magically crystalize in the mind but is so to speak sketched out in advance by the dispositions that allow things to appear to us as they do. Whereas Kant understood those dispositions as intellectual rules or procedures, Merleau-Ponty ascribes them to the bodily poise or readiness that gives us a felt sense rightness or equilibrium and so allows us to regard our own perceptions as either right or wrong, normal or skewed, true or false. ${ }^{3}$

Here we can see that, according to Carman, Merleau-Ponty's notion of bodily schema plays a similar function as Kant's schematism. Both are meant to explain how our experience is organized and how objectivity is constituted; our

\footnotetext{
${ }^{1}$ H. Dreyfus, "Overcoming the Myth of the Mental," p. 119.

2 S. Loidolt, "Naturalization of phenomenological pragmatism," in: O. Švec \& J. Čapek (eds.), Pragmatic Perspectives in Phenomenology, p. 127.

${ }^{3}$ T. Carman, "Sensation, judgement and phenomenal field," in: Roberto J. Carman et al. (ed.), The Cambridge Companion to Merleau-Ponty, p. 70.
} 
"dispositions 'allow" things to show up. The difference between them, says Carman, is that Kant's explanation is a purely intellectualistic one. Kantian schema is an explicit rule of intellectual synthesis, whereas Merleau-Ponty's bodily schema is "non-representational" and "non-cognitive." Now, that Merleau-Ponty's analysis is non-representational and non-cognitive (which differs him from Kant) is undoubtedly true. The problem, however, is that contrary to what Carman is saying, Merleau-Ponty's analysis is not analogous to Kant's in a much more substantive way since instead of revising Kant's strict dichotomy between organizing and organized elements of perception, MerleauPonty wanted to get rid of it.

According to Merleau-Ponty, Kant's project was to determine what we can know based on knowing who we are. His method was based on a presupposition that certain a priori structures are transcendental, i.e., they function as a form of our experience that cannot be deduced from it but make this experience possible in the first place. Investigation of who we are, therefore, takes in Kant a form of investigation of such conditions of experience. Ultimately, this led Kant to the assumption that such a form "embraces and constitutes the world": $: 1$ since the a priori cannot be deduced from experience but enables it as such, it must be ontologically prioritized. The a priori grounds the a posteriori. So, on the one side here we have a constituting transcendental subjectivity that imposes certain necessary categories on the world, and, on the other side, we have the world that receives this form, thus, becoming experienceable. What we have here, in other words, is a strict dichotomy between form and content, subject and object, a priori and a posteriori. The problem emphasized by Merleau-Ponty is that, eventually, this approach runs counter to Kant's own philosophical project that consisted in defining "our cognitive powers in terms of our factual condition." Because Kant's analysis of who we are has led him to a presupposition that we are essentially a consciousness that "surrounds" and "constitutes" the world, the very factuality of our being becomes unapproachable for him. If everything genuinely constitutive of subjectivity is a matter of necessary "must" and everything genuinely constitutive of the world is a matter of contingent "is", the "is" of subjectivity becomes essentially obscured, the empirical self becomes hopelessly detached from the transcendental, and the very situatedness or fact of our existence is rendered irrelevant.

What should be stressed against such an approach is that under no circumstances can we completely break free from the world and then start applicating our a priori constructions on it. If we endorsed this fact, namely, that

${ }^{1}$ M. Merleau-Ponty, Phenomenology of Perception, p. 353.

${ }^{2}$ Ibid., p. 256 
our experience is of essence worldly and positional, we would also have to admit that the fundamental starting point of Kant's project should be experience, i.e., the world itself as it appears to us, and not its conditions. Kantian apriorism remains a derivative and insufficient position: before being decomposed into a priori and a posteriori, experience must be already given, and any decomposition will always remain a second-order operation that is possible only because it has the world on the background. Kant's explanation has taken for granted what it was meant to explain: his reflexive approach does not really disclose constitutive principles of the world, but only "retraces the outline of a constitution of the world which is already realized." Experience - no matter how paradoxically it sounds - precedes its own conditions, and the phenomenological analysis must precede the logical one. If we are to explicate the "is" of subjectivity, in such a way, we must find a more primordial layer that is given before any distinction between a priori and a posteriori is introduced. Fundamental analysis of who we are must reveal not isolated a priori constructions, but a priori "in action" showing it as already engaged with the world. Speaking in Merleau-Ponty's terms, we must "set every conceivable being against the background of this world;" we must investigate the a priori "genealogically" within the context of our world. ${ }^{2}$

Pragmatist readers might follow Merleau-Ponty in his critique of Kantian transcendental "view from nowhere" and intellectualism, but, as we can see, the most fundamental element of Kant's system is remained intact: there still is a strict division between organizing and organized elements of experience, where the organizing principle is taken to have an epistemic and ontological priority. This is obvious from Carman's claim according to which bodily capacities and disposition establish both normatively and causally our perceptual orientation in the world. ${ }^{3}$ This is even more explicit in Dreyfus, who maintains that "brain architecture" ultimately explains what bodily capacities we have and that the "second-order" intentionality (if I may put it like this) consists in maximizing of reward, the basic rules of which are set by the brain: ("There are at least two ways the human body constrains the space of possible generalizations. The first is due to the brain; the second is due to how our lived body copes with things." ${ }^{4}$ So, it is our brain that explains the fact and modality of how we perceive colours, sizes and other qualities, and it is our body that stimulates us to attain a better position - simply because it can implement its

\footnotetext{
${ }^{1}$ Ibid., p. 351.

2 Ibid., p. 256.

${ }^{3}$ T. Carman, "Sensation, judgement and phenomenal field," p. 70.

${ }^{4}$ H. Dreyfus, "Merleau-Ponty and recent cognitive science," p. 237.
} 
capacities that are wired in the brain more optimally from there. The way experience is organized is not taken to be a part of "lived" experience; experience takes place in the world that has been already constituted by my brain. What we have here, in other words, is a classic relation of grounding: brain functions as an a priori that ultimately explains a posteriori experience.

Pragmatists, thus, substitute the subject/object dichotomy with organism/environment, but the substitution is still viewed as a constituting organism and a constituted environment. They, therefore, completely fail to follow Merleau-Ponty's main line of argument that consists in demonstrating the derivative character of the constituting/constituted opposition. Pragmatists trace experience back to its logical ground and, by doing so, they found every possible experience in something that does not appear in the experience but creates it as such. In this sense, Dreyfus's and Carman's description is not an objectivation of human experience, as S. Loidot has claimed, but its supplementation with an objectified ground that ultimately explains the content of lived experience. ${ }^{1}$ As we saw, however, Merleau-Ponty believes that a fundamental description must start with experience and not logical (or naturalistic, for what it matters) $)^{2}$ preconditions of experience. An approach that views the a priori as something that creates the conditions of its own application, an a priori that creates the world without being its part would necessarily remain insufficient. A fundamental reflection on the conditions of human existence must itself account for the fact that it is a part of this very existence. Having this in mind, we can finally get rid of a view from nowhere - a position that appears much more stubborn and illusive than many have expected.

\section{Time, world and ecstasy}

\section{a. Assumption of a way of existence}

How can we describe the a priori genealogically? How can we trace the genealogy of something given before any experience? The starting point, as we have seen, is to reformulate the very question: although necessary and irrefutable, the a priori cannot be said to be given before any experience. In fact, the

\footnotetext{
${ }^{1}$ Contrary to what Loidolt has argued, Dreyfus never really confused the questions of how the brain really works and how Dasein is there - he simply wanted to answer the second with the reference to first. This explains the ambiguity of pragmatists' use of the notion of body and brain.

${ }^{2}$ These two approaches can indeed be taken as synonymous in this regard: both try to explain the conditions of experience while not being part of this experience.
} 
only way it can be given is exactly through experience and, therefore, a priori categories still remain bound to the contingent features of the world. Let's once again take the example of colour perception. Our ability to grasp colours can never be reduced to the colours themselves. I must have an ability of seeing colours before I can spot some concrete empirical colour in the world. I can also formulate some necessary truth concerning colours like that all colours have saturation. In this sense, it is a priori. On the other side, colours are a real feature of the world. Taken by themselves, colours are not necessary, they are a posteriori, i.e., they belong to the world as something that well might have not existed. So, my a priori orientation, a bodily schema that makes it possible to organize my experience and that can be never deduced from experience does, in a sense, follow from the possibility of a certain experience, which the world offers to us. The a priori always unfolds based on a real possibility of a posteriori. Thus, Merleau-Ponty speaks of "the assumption of a form of existence" ${ }^{\text {- }}$ - attaining an a priori is an expression of a further, more primordial ontological movement. Instead of being exhausted by a set of a priori categories, human existence somehow attains them by transforming the worldly features onto the form of existence. What kind of ontological movement is it?

Consider, for example, the following quote:

"The very quality itself, in its specific texture, is the suggestion of a certain way of existing put to us, and responded to by us, in so far as we have sensory fields." 2

As we can see, according to Merleau-Ponty, a priori capacities as the ability to respond to certain qualities in the world can be deployed only insofar as we have sensual fields. Let me first say a few words about this notion. The simplest way to illustrate it is to revoke Gestaltists' analysis of the figure-background relation. A perception of a figure also presupposes an implicit perception of a background where this figure is placed. While the only thing that is given thematically is the figure itself, the background is also present, although in a different fashion. It is not a perception of any particular thing. There are no emphasized contours here. Merleau-Ponty describes it as "indeterminate vision," "a vision of something or other." ues the thematic perception. It solicits us to explore further what is there to be seen. A perception, in such a way, organizes a certain "field..., which can be

\footnotetext{
${ }^{1}$ M. Merleau-Ponty, Phenomenology of Perception, p. 257

${ }^{2}$ Ibid., p. 436.

${ }^{3}$ Ibid., p. 6.
} 
'surveyed:" ${ }^{1}$ no matter how abstract and primitive the perceived object is, our perception can never be completely sealed by its object but necessarily promises something more retaining, thus, a certain amount of freedom. It can go forwards and backwards revealing new entities and new perspectives.

More than this, the very identity of a perceived thing is sustained through this "indeterminate seeing." I see a chair because other chairs, a table, a fireplace and a room as such are also present in the background. If all other things were completely absent in my perception of the chair, the perception itself would collapse. I would no longer be sure if there is a backside of the chair, if it has four legs or only two, if I can sit on it, if its colour is grey or is rather the unusual lighting condition, etc. The chair would lose its "thingliness," it would be transformed into the fiction of the empiricist: a flat bundle of sensory stimulus that says nothing about the thing and only invites a consciousness to synthesise and judge in the odd Schneider's manner. The identity of things in perception, says Merleau-Ponty, is sustained through their horizons. Only because a thematic perception also contains non-thematic perception linked to the world, thus receiving its contextual meaning, the recognition in perception is possible. A perceptual field, therefore, is not a limitation placed upon our perception but a manifestation of the fact that our perception happens in the world and occupies a particular perspective. Things as such are never given to me entirely through perception but must be complemented or anticipated through the sensual fields. Perception, therefore, necessarily leaves a possibility to "infiltrate into the world in its entirety."

It should be obvious by now that this positional character of our perception is not a priori in the sense in which colour perception is. The fact that every experience must be placed in a perceptual field and somehow linked to other experiences does not carry with itself any kind of specific content. The perspectival character of our perception, our tendency to dispose perception into a figure-background relation is not a real feature of the world. It is the way we approach these features, thus, making possible their appearance as such. Can we, in this particular instance, talk about a classical Kantian a priori - an a priori that constitutes without being constituted? Not quite.

${ }^{1}$ Ibid., p. 34.

${ }^{2}$ Ibid., p. 384. 


\section{b. Temporal ecstasy}

In order to explicate the nature of perceptual fields and the role they play in organizing our perceptions, we should appeal to the final chapters of Phenomenology of Perception dedicated to the investigation of temporality. MerleauPonty raises two objections against the standard approaches to time. First, we cannot postulate time as something that we meet empirically. The temporal orientation always presupposes an observer for whom this time flows. The temporal orientation of the river flow, for example, follows from subjectivity that faces this flow. We could say both that temporal orientation complies with the flow (i.e., water flows from the past into future), and that it runs counter to the river, (i.e., that future of the river can be traced back to the creek where it originates). Second, we also cannot jump to the conclusion that the observer constitutes the time, which would be an intellectualistic antipode of the first mistake. If this were so, if timeliness was constituted by the transcendental subject, we would be once again completely detached from our empirical selves. What these two approaches, objectivistic and subjectivistic have in common is their tendency to view past, present and future as externally connected: either future pushes present into past or subject constitutes them as continuously changing each other. Both these approaches find themselves generating similarly structured paradoxes and completely fail to deal with our everyday experience. The adequate conception of time, says Merleau-Ponty, must account for the fact that time does not need any external ground in order to be constituted. Future flows into present and past not because something forces it into this movement. Time is essentially "affection of itself by itself," an idea that plays a key role in the architectonics of Phenomenology of Perception.

Let's take, for example, the way we perceive a tone while listening to a melody. What I hear is not an isolated sound that is connected to the past or to the future. Since the tone is given to me within the context of the melody, it carries with itself traces of the past tones and anticipations of the future ones. The past and the future here are neither intellectually postulated nor empirically discovered. The very tone we hear is endowed with a certain temporal logic that affects the way we perceive it. Here a primordial presence of time is disclosed explaining duration and change in themselves without grounding

\footnotetext{
${ }^{1}$ Ibid., p. 354. Merleau-Ponty quotes Heidegger's Kant und das Problem der Metaphysik, Friedrich Cohen, 1929, p. 180-181.
} 
them in a further phenomenon. ${ }^{1}$ Time appears as an internal connection of its different dimensions. The present of the sound presupposes its future and its past. Similarly, the past and the future reveals the same dependency: temporal dimensions are given within the unbreakable unity of time as such. Future, then, becomes past not because it is pushed out by another future and not because the transcendental subject constitutes this process behind my empirical back. Future becomes past because this is how future comes into being - as rapidly soaring into past. Similarly, "the past is a former future and a recent present" and "the present [is] an impending past and a recent future." ${ }^{2}$ The flow of time, a constant shift of future into past, thus, is not a result of some external pressure but a realization of the internal principle of time. It is essentially a synchronic movement, which progressively proliferates retaining its identity through such proliferation. We say that time is, claims Merleau-Ponty, "as we say that there is a fountain: the water changes while the fountain remains because its form is preserved."

The tone refers to the past and future because, taken by itself, it lacks an essential element in its identity. The identity of the tone includes non-identity: the tone becomes itself through relation to what it is not - the past and future tones. The contextual tone, in such a way, loses its own being-in-itself, its sealedness, thus, letting otherness to slip into its very core. Past and future occur because the tone disintegrates as this being-in-itself trying to recreate its unity through temporal horizons. The primordial unity here is supplanted with the quasi-unity, which is a project of re-unification within the context of a particular musical piece. A tone becomes aware of itself although in a very specific sense that is still to be clarified. It is constituted as an intention towards past and future, as "recognition" of this intention. The temporal ecstasy, says Merleau-Ponty, is the archetype of the relation of self to self: ${ }^{4}$ as internally connected to past and future, present must recognize its own inherent lack and strive for the complementation out of itself. This explains a distinctly anthropomorphic vocabulary Merleau-Ponty uses to describe the being of things (e.g. "the chimney, the walls, the table" that can "see"” the lamp on the table my emphasis.) ${ }^{5}$

Yet, the objective world is self-contained. It cannot give rise to past and future since they are the form of incompleteness of a present moment. Taken

\footnotetext{
${ }^{1}$ M. Merleau-Ponty, Phenomenology of Perception, p. 526

${ }^{2}$ Ibid., p. 490.

${ }^{3}$ Ibid.

${ }^{4}$ Ibid., p. 495.

${ }^{5}$ Ibid., p. 79.
} 
in itself, objectivity completely lacks negativity, a possibility of non-being that is required for such a disintegration. ${ }^{1}$ For objective fullness to be disintegrated, there must be a being that has never been such a fullness, that breaks objectivity according to its very being. In the very heart of time, in such a way, there must be a view, there must be somebody who would be able to take something in relation to something else. The being through which time comes into the world cannot have time as one of its predicates - otherwise, we would once again reinstantiate the Kantian problem - this entity is rather the time itself. What constitutes subjectivity is exactly such a disintegration, the inherent emptiness that attempts to compensate itself through essentially projective character of its existence. For it to be means to be aware to itself, that is to project its being onto past and future and to relate to itself from the temporal distance. A subject is nothing else but this temporalizing movement; "we must understand time as the subject and the subject as time." ${ }^{2}$ So, if an existing sound can become a part of a musical piece if it is projected onto past and future, the subject as this very movement of temporalization must project in order to obtain being as such; the sound can become disintegrated but the subjectivity simply is this disintegration.

We, thus, come to the central point of this article where Merleau-Ponty's neglect of the strict distinction between organizing and organized elements of perception can be explained. A free-floating temporality, a temporality that would somehow decide how to project itself based on a spontaneous decision has proven to be a self-defeating conception. The temporal movement cannot project anything out of itself because it lacks any objective content. In order to occur, it must find a shelter in something positive, in something that "is" there in the world. Subjectivity can realize itself as a temporal ecstasy only by "taking up some proposition of the world." What is disclosed by the projection, in other words, is the world itself that dictates how projection is to be realized. Temporal ecstasy gathers things together instead of constituting them. As we saw in the example of a melody, a tone does not contain any kind of imposition placed by the subject. It does not show traces of synthetic construction but refers simply to others based on its own identity. The sound, therefore, is not constituted but densified through the polarization into past-present-future structure. What subjectivity adds to things is simply openness towards the world. This is why Merleau-Ponty says that "Sinngebung", i.e., bestowal of

\footnotetext{
1 Ibid., p. 479.

2 Ibid., p. 490.

${ }^{3}$ Ibid., p. 510.
} 
sense, is "both centrifugal and centripetal:" a thing discloses its meaning through the subject (in this sense, significance is centrifugal, i.e., organized around the subject and held by it) but at the same time it sources directly from things themselves (in this sense, significance is centripetal). The present, thus, is projecting and projected at the same time because time "arises from my relation to things;", time must be melted with the world in order to occur.

This is how we should make sense of the embodied existence. It essentially is the "possibility of situations,"3 a way of establishing this relationship between time and the world. Body is an assimilated form of existence, a result of some propositions of the world have actually been taken up. This embodied existence is entirely guided by the worldly logic and necessarily stays within its frame - but the very possibility to be guided by something cannot be deduced from the world. In this sense, it might be useful to recall why MerleauPonty compares body and a piece of $\operatorname{art}^{4}$ before we proceed to the final passages. Both exist as a primordial co-dependence of organization (or expressing) and what is organized (or expressed). It is equally senseless to say that Van Gogh has painted shoes or that he painted with colours. The meaning of the picture arises out of the connection between these two real elements of the world. What the picture presents is neither colours nor shoes but a colourful way of being of the shoes. This way of being discloses its own meaning: the greyness of the picture expresses the solidity of shoes; the shades of white conveys the hard days of labour and rhythmic flow of rustic life. These real colours are meaningful, i.e., they are able to say something to us, insofar as they are indwelled by the world. On the other side, the meaning of the picture cannot be adequately translated into verbal, auditory or gustatory vocabularies since it sources exactly from the way colours exist in the world, the meaning they receive in the midst of things. The picture presents the colourful side of labour and rustic life, the colourful logic of this part of the world. There is an essential semblance between what is expressed and what is expressing: colours become meaningful through being enriched by the world (i.e., by being able to express something in it), but the world itself becomes accessible (i.e., it becomes capable of meaning anything) through being colourful. Van Gogh, in such a way, has crammed the world into colours at the cost of this world having a colourful flavour. By doing this he has melted the world and time: a real

\footnotetext{
${ }^{1}$ Ibid.

${ }^{2}$ Ibid., p. 478.

${ }^{3}$ Ibid., p. 475.

${ }^{4}$ Ibid., p. 175.
} 
feature of the world — colours - has become a form or organizing principle of this world.

Similarly, neither can the body be adequately separated from what is disclosed by it, nor what it discloses from the body. A world "in itself," a world grasped without any expression is meaningless and, eventually, unconceivable. Even less conceivable is the body if taken in isolation from what it expresses. Just as real colours were used by Van Gogh to encompass the world, bodily capacities employ the real features of the world for the same aim. Let's take an example of tactile perception. Such things as warmness, smoothness, sharpness or coolness, if taken as atomistic sensations, are strictly speaking unconceivable. Even at the most basic, abstract level sensations can be perceived only insofar as they are endowed with a certain temporal logic, which, as we have seen, is a matter of entrenching in the world. So, this nice coolness of a glass I hold in my hand is related to something being burning hot or freezing, states of perception that are not and can be not directly present at the same time. Because the world actually deploys this dispersion of temperatures, I can temporally encompass it and then locate something like coolness in the present moment. This grasp is existentially dependent upon the thermal dimension onto which it is projected. So, when I say that the glass is cool, I do not impose a psychological interpretation onto the causal substrate of sensation (which according to empiricist position is the only thing that is actually "felt"). There is no intellectual act of comparison between the current state and other possible states (not too hot, not too cold - therefore, cool) - I directly perceive coolness because perception as such is a temporal projection. If it were not, the very feeling would be transformed into "in itself", into a detectable causal stimulus, thus, losing the very possibility of explaining what perception is. $A$ single perception cannot be detached from the world it expresses, and neither can the world. What the thermal perception discloses is not things in themselves but a thermal side of the world, which guides my perception by its thermal logic. Particular things can appear to me only insofar as they display something like this thermal aspect, so I am able to disclose the cup as coolness, a touch as warmness and water as coldness. For a tactile organism, the world is indwelled with warmness and coldness because this is its way of communicating with it. Such an organism won't be capable of noticing weak sounds or electromagnetic waves simply because they do not display any thermal manifestation or display it minimally. To perceive, in this sense, means to present something with regard to the temperature, to encompass the world by letting it speak about itself in a certain modality.

Again, the crucial point is that perception as a temporal projection is not reducible to the world, but at the same time it draws its resources from the 
world. The temperature itself is nothing else but a particular position in the world. The movement of temporalization consists exactly in forcing the world in this particular worldly position. Temperature becomes a measure of the world while being a part of the world, an assimilated form of existence. The sensible, says Merleau-Ponty, "gives back to me what I lent to it, but this is only what I took from it in the first place." "The body is this ability to present things with regard to a particular perspective allowing transcendent things to accrete with their own meaning, i.e., to what they mean with regard to some particular perspective of colours, temperatures, etc. I am able to disclose transcendent things because they are disclosed in a modality akin to my body. I, thus, "co-exist" with things: I can perceive temperature or sounds because I am, in a sense, a temperature or because I am a sound; I can perceive anything only insofar as it reveals an essential semblance with my embodied being. So, Merleau-Ponty is saying that we can grasp a thing insofar as it is penetrated by the same logic we carry in our bodies: "A thing is ... internally taken up by us, reconstituted and experienced by us in so far as it is bound up with a world, the basic structures of which we carry with us." ${ }^{2}$ What we have here, in other words, is not a transcendental subject that imposes its subjective categories on the world, but a world that is seen from a particular worldly perspective of colours, tastes, forms, etc. The end result is a world presented with a particular flavour, i.e., a world that is penetrated by a particular position and for this reason presentable for this position. "As the co-existence of sentient and sensible, it [sensation] is itself constitutive of a setting for co-existence." ${ }^{3}$ Nothing is constituted here but rather is gathered together by the expressing power of this particular position.

\section{Conclusion: Maximum grip and the movement of temporalization}

We can see, finally, what exactly is wrong with pragmatists' picture of Merleau-Ponty and why their interpretation of the maximal grip serves as the most apparent indicator of the problem. Our tendency to get a maximal grip cannot be explained with the reference to the body because the body itself is explained through its ability to have a grip on things in the world. Dreyfus and Carman are guided by the presupposition (far more rooted in tradition than they are ready to acknowledge) that since I find the world already constituted, there

\footnotetext{
${ }^{1}$ Ibid., p. 249.

2 Ibid., p. 381.

${ }^{3}$ Ibid., p. 257.
} 
must be something other than me that has constituted it. They are convinced that Kant's dilemmas can be avoided if we transfer this constituting principle from "nowhere" to the world or from transcendental subjectivity to organisms and their bodies. The real problem, however, is not where this principle is located but the principle itself. By accepting the very idea that things need to be somehow constituted by organisms and their tendency to ensure the optimal habitat, pragmatic readers have already started off the wrong foot. Things are not constituted; they possess their own logic that is gathered by the temporal movement that is human subjectivity. Because Dreyfus and Carman are, in fact, guided by this line of questioning, they miss the real role that transcendence plays in Merleau-Ponty's analysis of things (this aspect was explored by J. Čapek).

Another part of the problem that I was trying to elaborate is that their neglect of the transcendence of things also undermines the transcendence of the body. As a part of the world, the body is guided by the real possibility of meaning that the world offers to us. My arm has the meaning it has, because the world is responsive to the possibility of grabbing and because things reveal their grabbing side. As this "possibility of situations," body is a capacity to extort the meaning from the world. It makes no sense to speak about constituting here just as it makes no sense to say that coolness is constituted because it is projected onto warmness and coldness. Transcendence, in other words, is not a realization of the body's internal principle but borrowing or assumption of this principle in the world. Imagine, for example, that we are stuck in a dark room. Since the visual grip is no longer possible, the very meaning of our body alters. Now, I use my hands as walking sticks; my movements are slow, unsure and careful. The whole structure of orientation is changed. Because the world is no longer able to show its visible side to me, the meaning of my body changes as radically as the world itself. The temporal ecstasy is now realized differently, and it is the "sensible" that offers to the temporal ecstasy the form of realization. The pragmatists' explanation, in such a way, stops halfway. They do emphasize that body receives its specific meaning based on its inherent "teleology"1 consisting in the tendency to get a grip on the world. What they miss, however, is that this inherent teleology is itself promised by the world; it is an explication of a possibility that was already there.

This oversight prevents pragmatists from escaping a transcendental paradigm, which they are so desperate to part ways with, and precludes them from seeing one of the most innovative insights that Merleau-Ponty has. A priori

${ }^{1}$ Ibid., p. 376. 
constructions, schemes and skills are not themselves seen as a final explanation. They are put at the service of openness and draw their legitimacy and value from such an openness; they are means through which subjectivity gets a footing in the world and they are meaningful to the extent they enable such a footing. Consequently, we can differentiate between more and less optimal a priori constructions and their more or less optimal uses. This is why, I think, Merleau-Ponty speaks not of optimal but of maximal grip: if the notion of optimality is explained by a subject for whom something is optimal, the notion of maximal grip explains subject itself as a tendency to get the vastest possible temporal grip on the world. Sight, for example, offers richer access to the world than tactile perception. So, even though the meaning of my body is changed if I am placed in a dark room, the situation itself remains suboptimal. I will orient through my tactile capacities, but I will look for a switch because sight offers me a better, more extensive grip on the world. The reason is that the dark undifferentiated environment around me can be projected onto the past and future less extensively. The only future of this particular situation is the possibility of bumping into doors and tables and the only past is the doors and tables I have failed to avoid. Once the light is turned on, the situation changes drastically. Now, the room refers me to the endless possibilities of using various things that are directly accessible to me. We are dealing with a more extensive temporal ecstasy, i.e., ecstasy that embeds in itself more of a world and, thus, offers a more extensive realization of myself as a subject. Optimal grip, thus, is not "prescribed by my body;" it is not a realization of internal law that is wired in brain. It is rather a prospective of consolidation or maximization of subjectivity and its world.

Acknowledgment This work was supported by the European Regional Development Fund-Project "Creativity and Adaptability as Conditions of the Success of Europe in an Interrelated World" (No. CZ.02.1.01/0.0/0.0/16_019/ 0000734).

\section{References}

Čapek J. (2020), "Perceptual Faith beyond Practical Involvement," in: J. Čapek \& O. Švec (eds.), Pragmatic Perspectives in Phenomenology, Routledge. 
Carman T. (2014), "Sensation, Judgement and Phenomenal Field," in: T. Carman \& M.B.N. Hansen (eds.), The Cambridge Companion to Merleau-Ponty, Cambridge University Press.

Berendzen J.C. (2010), “Coping Without Foundations: On Dreyfus's Use of MerleauPonty," International Journal of Philosophical Studies, Vol. 18(5).

Dreyfus H. (2014), "Overcoming the Myth of the Mental," in: M. Wrathall (ed.), Skillful Coping, Oxford University Press.

Dreyfus H. (2014), "Merleau-Ponty and Recent Cognitive Science," in: M. Wrathall (ed.), Skillful coping, Oxford University Press.

Heidegger M. (1929), Kant und das Problem der Metaphysik, Friedrich Cohen.

Kelly S. (2004), "Seeing Things in Merleau-Ponty," in: T. Carman \& M.B.N. Hansen (eds.), The Cambridge Companion to Merleau-Ponty, Cambridge University Press.

Loidolt S. (2020), "Naturalization of Phenomenological Pragmatism," in: J. Capek \& O. Švec (eds.), Pragmatic Perspectives in Phenomenology, Routledge.

Merleau-Ponty M. (1962), Phenomenology of Perception, Routledge \& Kegan Paul.

Romdenh-Romluc K. (2012), "Thought in Action," in: D. Zahavi (ed.), The Oxford Handbook of Contemporary Phenomenology, Oxford University Press.

Švec O. (2020), "Situated Acting and Embodied Coping," Pragmatism Today, Vol. 11, 2. 